\title{
Horner's syndrome: an electron microscopic study of a human iris
}

\author{
A C E McCartney, P Riordan-Eva, R C Howes, D J Spalton
}

\begin{abstract}
Electron microscopy was performed on the irides of a man with a history of a long standing Horner's syndrome which resulted in iris heterochromia. Comparison of his normal brown iris with the depigmented blue iris showed depletion of anterior border cells and absence of sympathetic nerve fibres. Stromal melanocyte numbers were also diminished but melanosome numbers within the residual cells were not significantly different. Postnatal maintenance of stromal and anterior border zone pigmentation, derived from the neural crest, would appear to be dependent on an intact sympathetic nerve supply in contrast to the iris pigment epithelium which remains normally unaffected in Horner's syndrome. (Brf Ophthalmol 1992; 76: 746-749)
\end{abstract}

The association of paresis of the cervical sympathetic nerve supply with heterochromia of the iris in Horner's syndrome was described by Calhoun in 1919, who reported his series of experiments on rabbits and other rodents, and showed that depletion of iris pigmentation was related to length of survival after sympathectomy. ${ }^{1} \mathrm{He}$ compared his results in animals with data from humans, noting especially the effects of forceps delivery in the induction of Horner's syndrome which had been described in 1875 , as consisting of ptosis, miosis, anhidrosis, and facial hemiatrophy. At the time of his paper there had been no histopathological examination of a human decolorised iris and such specimens remain rare. This paper describes the ultrastructural changes in one such case.

Institute of

Ophthalmology, London

A C E McCartney

R C Howes

St Thomas's Hospital, London

P Riordan-Eva ${ }^{\star}$

D J Spalton

Correspondence to:

Dr Alison McCartney,

Institute of Ophthalmology, 17-25 Cayton Street, London ECIV 9AT.

^Current address: Moorfields Eye Hospital, London ECl.

Accepted for publication 22 June 1992 relevant neurological findings.

Postoperatively the patient failed to recover consciousness. Computed tomographic scanning revealed multiple infarcts throughout the cerebral hemispheres, the cerebellum, and brainstem. Repeated neurological examination failed to show any improvement and, at the request of the family, the patient was extubated during the fourth postoperative week. He died shortly thereafter.

Formal pharmacological testing was carried out during the postoperative period. Testing with $4 \%$ cocaine confirmed the left sided Horner's syndrome, with failure to dilate to hydroxyamphetamine suggesting a postganglionic lesion. Supersensitivity to phenylephrine and facial anhidrosis were not investigated.

\section{Histopathology}

After removal of the corneas for donor material, the eyes were fixed in glutaraldehyde and sections were taken. The normal right eye was a light brown colour with several freckles of a deeper brown hue. The left affected eye had a pale blue grey iris, with a focal area of browner colour around the pupil and three prominent iris naevi (Fig $1 \mathrm{~A}$ and B). Sections were taken from the normal brown eye, the blue areas of the affected eye, the slightly more normochromic area of the affected eye and the iris naevi. Light and transmission electron microscopy (TEM) were carried out.

Iris pigmentation is conferred by the cells of the anterior border and stroma. Heterochromia may arise either as a result of reduction in the number or volume of melanocytes, or the number or volume of the specific organelles (the melanosomes) within those cells. ${ }^{2}$ Quantitation of the number of pigmented melanocytes in the anterior border and stroma was performed by computerised image analysis and comparisons were made between the normal contralateral brown iris and the blue and brown areas in the affected iris. The number of clump cells was also measured. Using electron microscopy at a magnification of 1200 , the number and size of the melanosomes per unit volume of melanocyte cytoplasm were measured. TEM was also used to search for the presence of axons within the iris, especially in the anterior border in juxtaposition to melanocytes.

The iris pigment epithelium was also examined in each eye.

\section{Results}

Melanocytes in the anterior border and stroma were greatly diminished in the affected left eye compared with the normal right brown eye. This can be seen in the photomicrographs of the 
Figure 1 (A) Affected 'blue' eye: note miotic pupil, with focal peripupillary retention of original colour and three iris naevi. $(B)$ Unaffected 'control' brown eye with unconstricted pupil and well defined iris collarette.

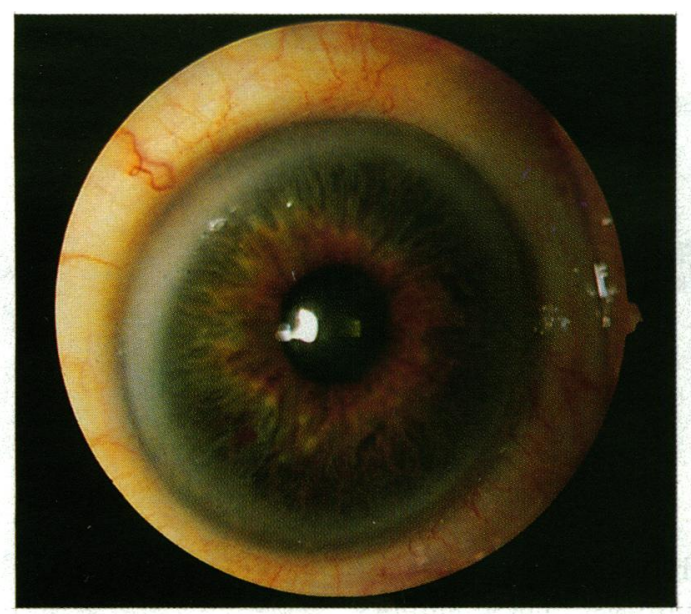

Fig $1 A$

toludine blue stained semi-thin sections taken at the same magnification (Fig 2A and B).

Quantitative image analysis shows that the number of cells in the anterior border per $\mathrm{mm}$ in the 'blue' anterior border of the affected eye is equivalent to $3204 / \mathrm{mm}^{2}$ and in the unaffected eye $8005 / \mathrm{mm}^{2}$. There was also a decrease in the number of stromal melanocytes. The number of cells in the stroma was $1380 / \mathrm{mm}^{2}$ in the normal eye which is within the range of values which gave a mean of $1031 / \mathrm{mm}^{2}$ in a previous set of irises used as controls. ${ }^{2}$ The number of stromal cells in the affected iris of this patient was $349 / \mathrm{mm}^{2}$.

Both the anterior border and the stroma therefore showed a fall in the number of pigmented cells.

The apparent volume of cytoplasm of these cells did not appear to alter, the cells were of the same shape although fewer in number (Fig 3A and B). (The rounding up of processes was not as marked as in Fuchs' heterochromia.) The mean number of melanosomes was $44 \cdot 6$ (SD 2.1) per cell in the affected eye compared with $50 \cdot 1$ (SD $2 \cdot 3$ ) in the control eye.

There were three naevi in the affected iris. These appeared to contain more cells per $\mathrm{mm}^{2}$ and the number of melanosomes per cell was slightly increased at 55 per cell. They also contained fewer type III (slightly immature) melanosomes than the brown eye melanocytes. Both normal and affected eyes contained clump cells (macrophages that engulf liberated melanin); these contained both small melano-

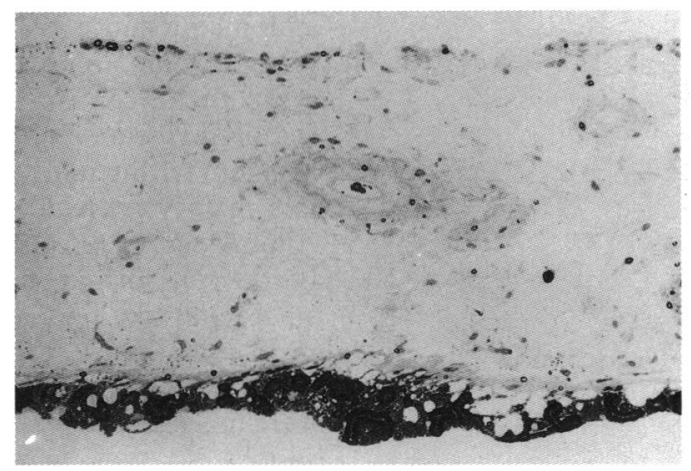

Fig $2 A$

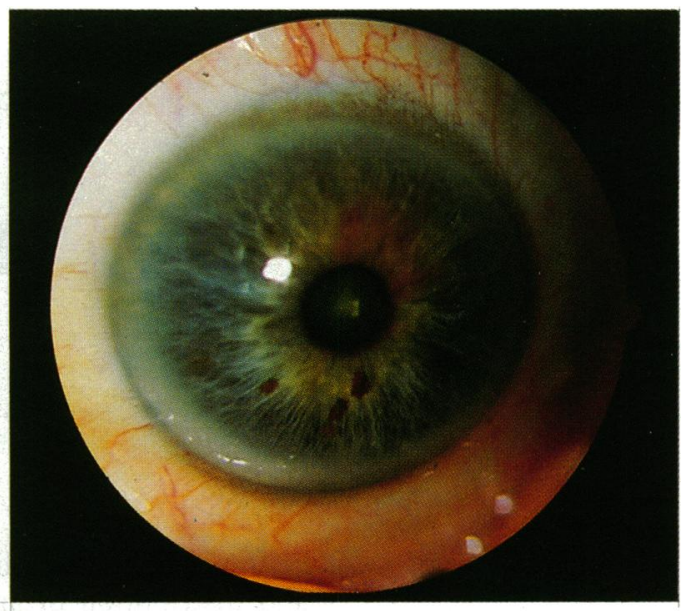

Fig $1 B$

somes derived from cells of neural crest origin (anterior border and stromal cells) and also large melanosomes from iris pigment epithelial cells, as well as lipid laden phagosomes (Fig 4). The iris pigment epithelial cells did not differ in the two eyes.

Axons were demonstrably entwined amongst the processes of the anterior border cells in the unaffected eye but not in the affected eye. They could be recognised by granulated vesicles similar to those illustrated by Mukano, ${ }^{3}$ and conformed to his description of adrenergic nerves though there was some loss of cellular architecture owing to slightly delayed fixation (Fig 5). Myelinated nerve fibres were present in both eyes (Fig 6).

There was therefore a decrease in the number of melanocytes present in the anterior border and stroma of the affected eye and a slight reduction in the number of organelles. There was also an apparent lack of sympathetic axons.

\section{Discussion}

This patient had a Horner's syndrome with depigmentation of the affected iris. We do not know that it was of congenital origin but it had been present for at least 40 years. The diagnosis was confirmed pharmacologically and testing with hydroxyamphetamine showed no reaction, suggesting a postganglionic localisation of the lesion. The interpretation of pharmacological tests in congenital Horner's syndrome is complicated by trans-synaptic degeneration and must

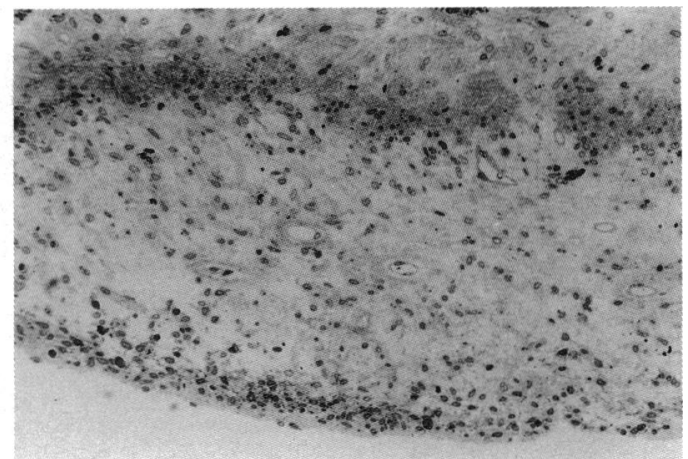

Fig 2B 
Figure 3 Electron micrographs of anterior border of affected $(A)$ and control $(B)$ iris showing atrophic anterior border with fewer cells and no evidence of complex interdigitations in $(A)$ when compared with (B). Cells and nuclei are of similar size but a clump cell is present in the lower right hand corner of $(A)$ the affected iris.

Figure 4 Another pair of clump cells, close to the anterior border in the brown control eye, containing lipid filled phagosomes and melanosomes within vacuoles. The melanosomes are of both anterior border or stromal melanocytic origin and a large pigment epithelial melanosome is also present. The complex interdigitations of the anterior border cells, within which unmyelinated nerves lie are also seen. TEM $\times 3255$.

Figure 5 Sympathetic unmyelinated axons lying adjacent to anterior border melanocyte processes in control unaffected eye. $T E M \times 12800$.
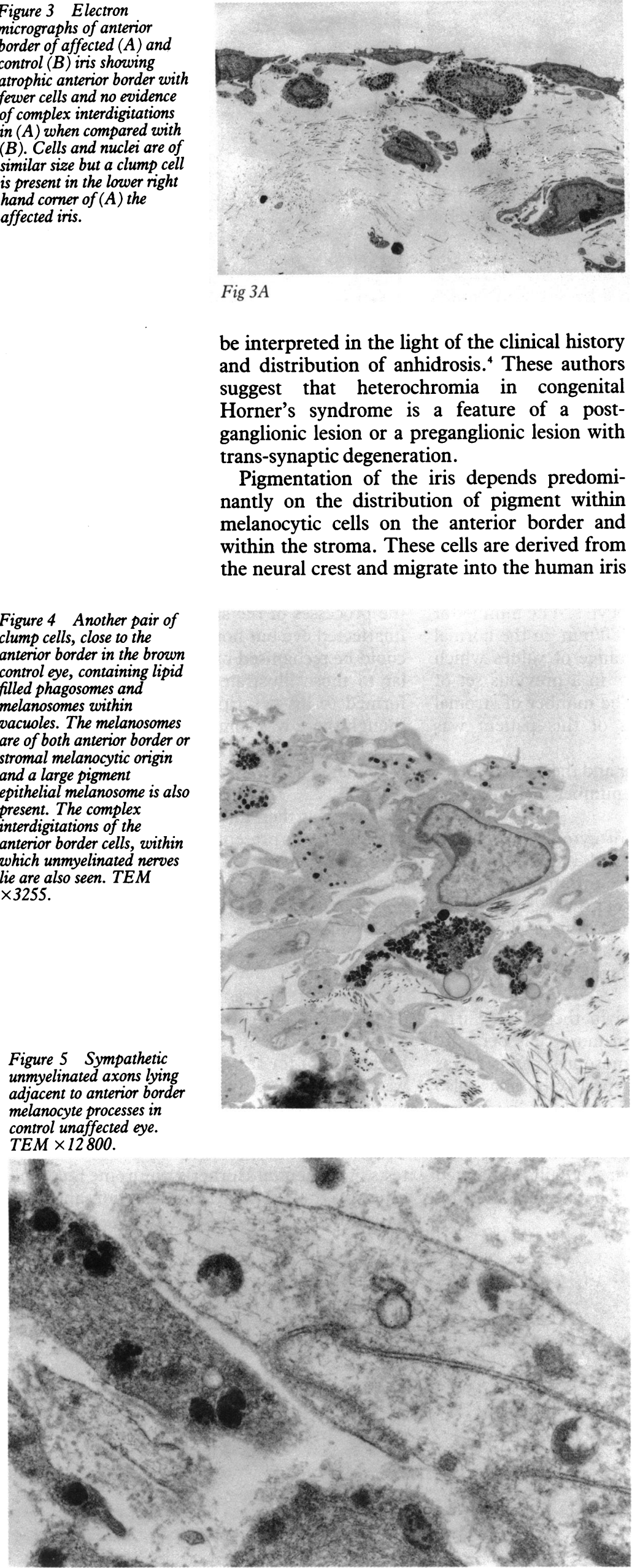

Fig $3 A$

be interpreted in the light of the clinical history and distribution of anhidrosis. ${ }^{4}$ These authors suggest that heterochromia in congenital Horner's syndrome is a feature of a postganglionic lesion or a preganglionic lesion with trans-synaptic degeneration.

Pigmentation of the iris depends predominantly on the distribution of pigment within melanocytic cells on the anterior border and within the stroma. These cells are derived from the neural crest and migrate into the human iris

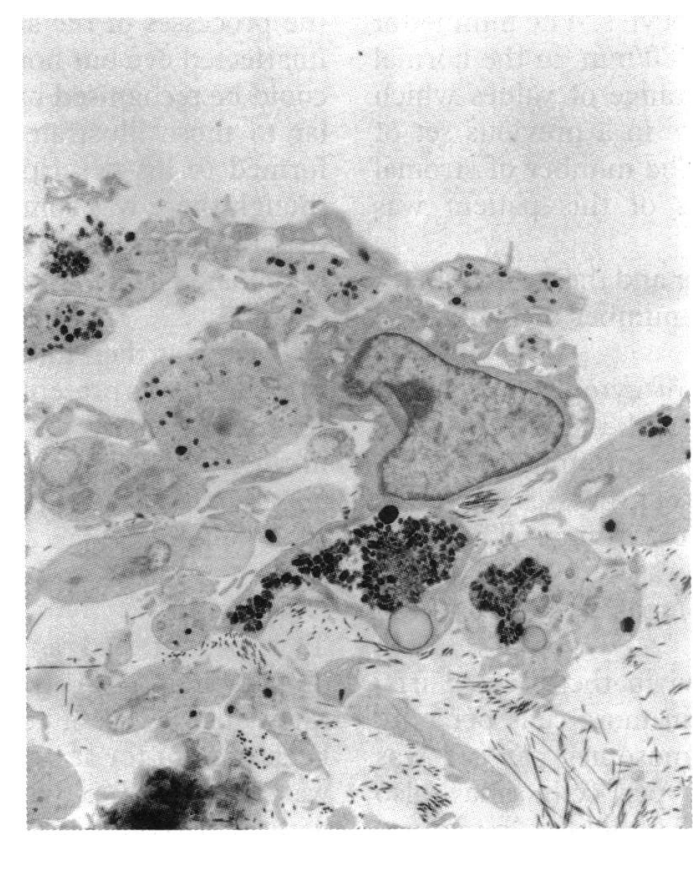

late in gestation, and postnatally so that full pigmentation is not normally present until 9 months after birth. The iris pigment epithelium is derived from the primary optic vesicle and these cells and their much larger melanosome organelles are not dependent on the sympathetic nervous system and are present 6 weeks after conception. The migration of all neural crest cells is presumed to be preprogrammed but the end stage distribution and changes in cell shape from the spindled migrating cells to the sessile dendritic cells may be influenced by local trophic factors. Sympathetic control of migration and distribution of the cells responsible for skin pigmentation are not present in higher mammals, in contrast to amphibians and reptiles which can respond rapidly to threat, by camouflage. Strangely the trophic mechanism modulated by the sympathetic nervous system is retained within the eye, though swift changes of colour are not, of course, seen. Melanocytes of the eye are regarded as being continent in contrast to those of the skin as they do not donate melanin to other cells or shed it in cycles in response to actinic stimulation. Their tyrosine dependent metabolism is therefore reduced compared with skin melanocytes. Fading of iris colour occurs with age and heterochromia can arise as a result of inflammation. ${ }^{2}$ Both migration and maintenance of neural crest derived iris pigment containing cells appear to be under sympathetic control since both congenital and acquired Horner's syndromes lead to lack or loss of colour within the affected iris, though this may take many years to develop with acquired lesions. Anomalous or neoplastic groups of anterior border cells forming naevi may be autoregulatory since persistent pigmentation has been described in the iris naevi of a patient with Horner's syndrome $^{5}$ as in our case. Sympathetic nerves were not seen in association with the naevi in our case.

Though there are numerous clinical descrip- 


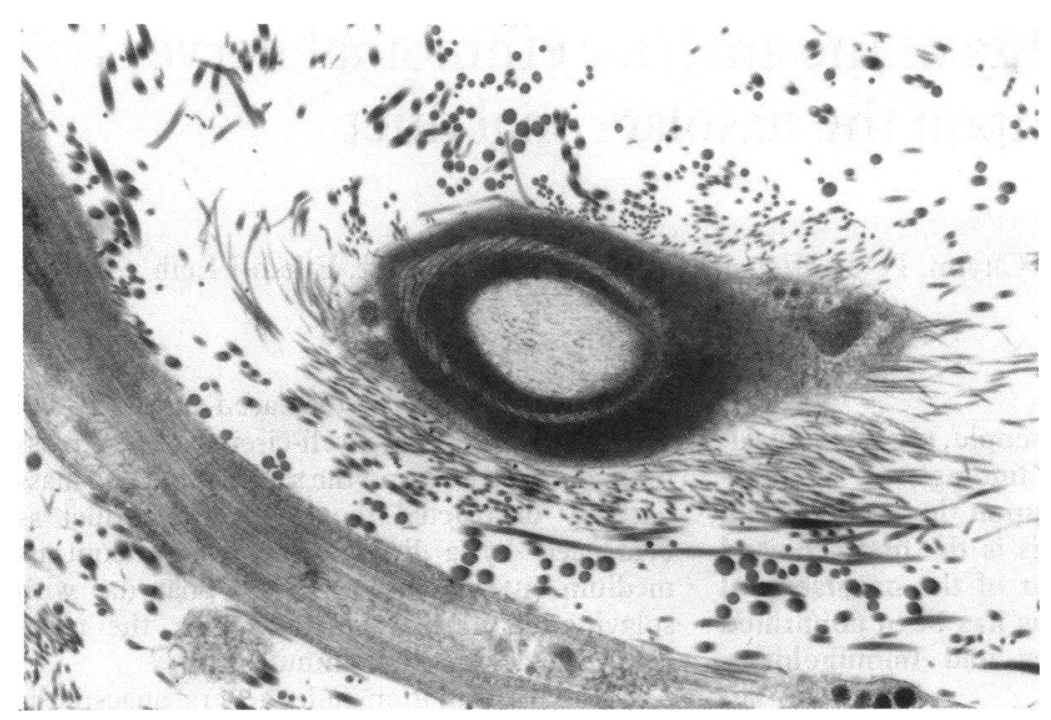

Figure 6 Myelinated nerve in stroma of control eye. Similar fibres were present in the affected eye. TEM $\times 5300$. tions of the effects of sympathetic denervation of the iris, histopathologic descriptions are rare on human material and most observations have been on animal models. ${ }^{6}$ Calhoun quotes the work of Bistis who examined four rabbit eyes ${ }^{7}$ and showed that there was reduction of stromal pigmentation with rounded or oval nuclei after sympathectomy. Both Laties ${ }^{89}$ and Ringvold ${ }^{10}$ show that in animals there is an intimate spatial relationship between the adrenergic neurons and iris melanocytes, especially those on the anterior border of the iris. Mukano ${ }^{3}$ has shown in an electron microscopic study of the nerve terminals to normal melanocytes in the stroma of the normal iris, that there are four different types of terminal present. Those associated with the sympathetic nervous system consist of granulated or empty vesicles $60-110 \mathrm{~nm}$ in diameter separated by a basement membrane lying about $75 \mathrm{~nm}$ from the melanocytes and others more intimately associated with melanocytes only separated by a $25 \mathrm{~nm}$ gap. Two further types of terminal, thought to be parasympathetic, were also observed. Vasoactive intestinal peptide nerve fibres are also present, ${ }^{11}$ probably running co-axially. Pharmacologically the action of the $\alpha$ adrenergic receptors appears to be more important than the $\beta .{ }^{12}$

Our results show that there is an apparent absence of sympathetic neurons in the affected eye as would be expected, and that there is a decrease in the number of cells derived from the neural crest but not of intracellular organelles. This may be due to a failure of cellular migration if the denervation occurred at or about the time of birth as seems possible, but there must have been some migration otherwise no pigmented cells would have been present. Another explanation would be that failure of sympathetic innervation leads to attrition of the normal cell population, but this is unlikely as hypochromia only occurs mildly and after many years with acquired Horner's syndrome whereas it is seen in infants with congenital Horner's syndrome. Active cellular loss, however, may be occurring since clump cells were normal or possibly slightly increased in number suggesting increased turnover, or greater cell loss on the affected side.

There were three naevi present and these were heavily pigmented. These may represent clumping of cells that were in the process of migrating but came to rest prematurely or they may represent an autonomous group of neoplastic cells which do not require the actions of the sympathetic nervous system to maintain their degree of pigmentation.

It is likely that this patient had a congenital partial post-ganglionic lesion followed by loss of normal postnatal migration. This would account for the widespread heterochromia as well as explaining the focal retention of pigmentation around the circumference of the pupillary margin. This latter area would contain the cells most likely to have migrated and subsequently become able to form pigment before denervation occurred leading to failure of pigmentation in the rest of the iris.

1 Calhoun FP. Causes of heterochromia iridis with special reference to paralysis of the cervical sympathetic. Am $\mathcal{F}$ Ophthalmol 1919; 2: 255-69.

2 McCartney ACE, Bull TB, Spalton DJ. Fuchs' heterochromic cyclitis: an electron microscopic study. Trans Ophthalmol Soc UK 1986; 105: 324-9.

3 Mukano K, Witmer R. Innervation of melanocytes in human iris. An electron microscopic study. Graefes Arch Clin Exp Ophthalmol 1977; 203: 1-8

4 Weinstein JM, Zweifel TJ, Thompson HS. Congenital Horner's syndrome. Arch Ophthalmol 1980; 98: 1074-8.

5 Dryja TP, Albert DM. Lack of adrenergic influence on the pigmentation of iris nevus cells. Arch Ophthalmol 1980; 98: 1996.

6 Lowenfield IE, Thompson HA. Fuchs's heterochromic cyclitis. A critical review of the literature. II. Etiology and mechanisms. Surv Ophthalmol 1973; 18: 2-61.

7 Bistis J. Etude clinique et experimentale sur le role du sympathetique dans l'etiologie de l'heterochromie. Arch sympathetique dans l'etiologie
d'Ophtalmol 1928; 32: 569-94.

8 Laties A. Ocular melanin and the adrenergic innervation to the eye. Trans Am Ophthalmol Soc 1974; 72: 560-605.

9 Laties A, Lerner A. Iris colour and relationship of tyrosinase activity to adrenergic innervation. Nature $1975 ; 255$ : 152-3.

10 Ringvold A. Electron microscopic study of the iris stroma in monkey and rabbit with particular reference to intercellular contacts and sympathetic innervation of anterior layer cells. Exp Eye Res 1975; 20: 349-65.

11 Stone RA, Tervo $T$, Tervo $\mathrm{K}$, Tarkkanen A. Vasoactive intestinal polypeptide-like immunoreactive nerves to the human eye. Acta Ophthalmol (Kbh) 1986; 64: 12-8.

12 Odin L, O'Donnell FE. Adrenergic influence on iris stromal pigmentation: evidence for alpha-adrenergic receptors. Invest Ophthalmol Vis Sci 1982; 32: 528-30. 